\title{
Editorial
}

Obesity and Metabolic Syndrome

Diabetes Metab J 2019;43:407-409

https://doi.org/10.4093/dmj.2019.0141

pISSN 2233-6079 · eISSN 2233-6087

DIABET\&S \& METABOLISM JOURNAL

\section{Changes in Metabolic Profile Over Time: Impact on the Risk of Diabetes}

\author{
Yunjung Cho ${ }^{1}$, Seung-Hwan Lee ${ }^{1,2}$ \\ ${ }^{1}$ Division of Endocrinology and Metabolism, Department of Internal Medicine, Seoul St. Mary's Hospital, College of Medicine, The Catholic University of \\ Korea, Seoul, \\ ${ }^{2}$ Department of Medical Informatics, College of Medicine, The Catholic University of Korea, Seoul, Korea
}

Metabolic syndrome (MetS), characterized by insulin resistance, glucose intolerance, abdominal obesity, atherogenic dyslipidemia, elevated blood pressure and proinflammatory and prothrombotic state, is well known to increase the risk of type 2 diabetes mellitus and cardiovascular diseases [1,2]. Because these outcomes are highly prevalent and lead to enormous health and socioeconomic burden worldwide, correction of metabolic derangement is a challenging but unavoidable goal of patient management.

In the article entitled "Impact of longitudinal changes in metabolic syndrome status over 2 years on 10-year incident diabetes mellitus," Huh et al. [3] examined whether changes in MetS status over 2 years can modify future risk of diabetes using a prospective cohort of 7,317 participants. They were divided into four groups, two without changes (non-MetS, persistent MetS) and two with changes (resolved MetS, incident MetS). Although the baseline metabolic profiles were closer to persistent MetS group, the risk of incident diabetes was lowered in resolved MetS group and insignificant compared with non-MetS group in fully adjusted model. The hazard ratios were similar in incident MetS group and persistent MetS group. Similar studies had been performed in Korean subjects with different parameters of metabolic derangement. The risk of diabetes according to changes in body weight was examined in a study of 51,405 non-diabetic subjects using the National Health Insurance Service claim database [4]. When obesity was defined using the body mass index (BMI) cutoff of $25 \mathrm{~kg} / \mathrm{m}^{2}$, subjects who moved from obese to nonobese category still had significantly higher risk of diabetes compared with consistently nonobese group. However, when the risk was evaluated according to the percentage changes in BMI, more than 3\% decrease in nonobese subjects or more than $9 \%$ decrease in obese subjects were associated with lower risk of diabetes. Another study of 2,692 non-diabetic individuals in a population-based prospective cohort study used a simple triglyceride-glucose (TyG) index, a product of fasting glucose and triglycerides, as a surrogate marker of insulin resistance [5]. When the risk of developing diabetes during a 8-year follow-up was assessed according to the changes in TyG index over 4 years, improvement of TyG index from highest quartile group to lower three quartile groups resulted in lowered risk of diabetes, which was similar to subjects who had consistently low TyG index. Collectively, it seems that reverting obesity and insulin resistance is beneficial for the prevention of future diabetes, and Huh et al. [3] provide an important addition to the previous data.

There are some remaining questions that warrants further exploration. (1) What is the minimum required amount of body weight reduction or metabolic parameter improvement for a significant beneficial effect? In the Diabetes Prevention Program study, lifestyle modification program aimed at least a 7\% weight loss and at least 150 minutes of physical activity per week. At the end of a 24 -week curriculum, $50 \%$ of the participants in the lifestyle intervention group achieved weight loss of $7 \%$ or more, and the incidence of diabetes were reduced by
Corresponding author: Seung-Hwan Lee (iD https://orcid.org/0000-0002-3964-3877 Division of Endocrinology and Metabolism, Department of Internal Medicine, Seoul St. Mary's Hospital, College of Medicine, The Catholic University of Korea, 222 Banpo-daero, Seocho-gu, Seoul 06591, Korea

E-mail: hwanx2@catholic.ac.kr
This is an Open Access article distributed under the terms of the Creative Commons Attribution Non-Commercial License (http://creativecommons.org/licenses/by-nc/4.0/) which permits unrestricted non-commercial use, distribution, and reproduction in any medium, provided the original work is properly cited. 
58\% compared with placebo group [6]. The Look Action for Health for Diabetes (AHEAD) study which also aimed at achieving and maintaining weight loss of at least $7 \%$ and Diabetes Remission Clinical Trial (DiRECT) which aimed at weight loss of more than $15 \mathrm{~kg}$ even showed significantly higher chance of diabetes remission compared with control group $[7,8]$. Of note, it is likely that the dose-response relationship between weight loss or metabolic improvement and the prevention of diabetes is unequal among different ethnicities or at an individual level. The concept of 'personal fat threshold' suggests that there might be an individual level of susceptibility affecting ectopic fat accumulation and insulin resistance [9]. Because community-based and hospital-based Korean Diabetes Prevention Study is under way, it would be interesting to find out the optimal extent of lifestyle modification for reducing the risk of diabetes in Koreans $[10,11]$. (2) What is the most feasible and effective method of intervention? Although lifestyle intervention has been regarded as a key factor with proven efficacy [6-8], maintaining weight loss is unsuccessful in many cases. Recently, newer methods or pharmacological agents have demonstrated impressive effect on diabetes prevention. A 15-year follow-up study of bariatric surgery showed $83 \%$ reduction of incident diabetes in Swedish obese subjects [12]. In obese subjects with prediabetes, administration of liraglutide $3.0 \mathrm{mg}$ for 160 weeks on top of lifestyle intervention led to $79 \%$ reduction in diabetes development compared with placebo [13]. These data open a possibility of adopting multiple different combinations of measures to achieve metabolic health and weight loss. (3) Does the exposure duration to obesity or MetS affect the reversal capacity? Several studies demonstrated positive associations between the duration or timing of obesity and the risk of diabetes $[14,15]$. However, whether people with different duration of obesity or MetS have different response to interventions for diabetes prevention seems to be unclear at this point.

Accumulating evidence support the importance of reverting obesity and MetS and keeping below the threshold of diabetes risk. It would be crucial for physicians to keep eyes on patients' MetS status and to strive to find effective management and education methods for correcting risk factors and preventing adverse health outcomes. Considering the epidemic of obesity and diabetes, implementation of community-based effort is critical and would be a fundamental approach.

\section{CONFLICTS OF INTEREST}

No potential conflict of interest relevant to this article was reported.

\section{REFERENCES}

1. Grundy SM, Brewer HB Jr, Cleeman JI, Smith SC Jr, Lenfant C; American Heart Association; National Heart, Lung, and Blood Institute. Definition of metabolic syndrome: report of the National Heart, Lung, and Blood Institute/American Heart Association conference on scientific issues related to definition. Circulation 2004;109:433-8.

2. Shin JA, Lee JH, Lim SY, Ha HS, Kwon HS, Park YM, Lee WC, Kang MI, Yim HW, Yoon KH, Son HY. Metabolic syndrome as a predictor of type 2 diabetes, and its clinical interpretations and usefulness. J Diabetes Investig 2013;4:334-43.

3. Huh JH, Ahn SG, Kim YI, Go T, Sung KC, Choi JH, Koh KK, Kim JY. Impact of longitudinal changes in metabolic syndrome status over 2 years on 10-year incident diabetes mellitus. Diabetes Metab J 2019;43:530-8.

4. Kim ES, Jeong JS, Han K, Kim MK, Lee SH, Park YM, Baek $\mathrm{KH}$, Moon SD, Han JH, Song KH, Kwon HS. Impact of weight changes on the incidence of diabetes mellitus: a Korean nationwide cohort study. Sci Rep 2018;8:3735.

5. Lee SH, Yang HK, Ha HS, Lee JH, Kwon HS, Park YM, Yim HW, Kang MI, Lee WC, Son HY, Yoon KH. Changes in metabolic health status over time and risk of developing type 2 diabetes: a prospective cohort study. Medicine (Baltimore) 2015; 94:e1705.

6. Knowler WC, Barrett-Connor E, Fowler SE, Hamman RF, Lachin JM, Walker EA, Nathan DM; Diabetes Prevention Program Research Group. Reduction in the incidence of type 2 diabetes with lifestyle intervention or metformin. N Engl J Med 2002;346:393-403.

7. Gregg EW, Chen H, Wagenknecht LE, Clark JM, Delahanty LM, Bantle J, Pownall HJ, Johnson KC, Safford MM, Kitabchi AE, Pi-Sunyer FX, Wing RR, Bertoni AG; Look AHEAD Research Group. Association of an intensive lifestyle intervention with remission of type 2 diabetes. JAMA 2012;308:2489-96.

8. Lean MEJ, Leslie WS, Barnes AC, Brosnahan N, Thom G, McCombie L, Peters C, Zhyzhneuskaya S, Al-Mrabeh A, Hollingsworth KG, Rodrigues AM, Rehackova L, Adamson AJ, Sniehotta FF, Mathers JC, Ross HM, McIlvenna Y, Welsh P, Kean S, Ford I, McConnachie A, Messow CM, Sattar N, Taylor R. Du- 
rability of a primary care-led weight-management intervention for remission of type 2 diabetes: 2 -year results of the DiRECT open-label, cluster-randomised trial. Lancet Diabetes Endocrinol 2019;7:344-55.

9. Taylor R, Holman RR. Normal weight individuals who develop type 2 diabetes: the personal fat threshold. Clin Sci (Lond) 2015; 128:405-10.

10. Cha SA, Lim SY, Kim KR, Lee EY, Kang B, Choi YH, Yoon KH, Ahn YB, Lee JH, Ko SH. Community-based randomized controlled trial of diabetes prevention study for high-risk individuals of type 2 diabetes: lifestyle intervention using web-based system. BMC Public Health 2017;17:387.

11. Rhee SY, Chon S, Ahn KJ, Woo JT; Korean Diabetes Prevention Study Investigators. Hospital-based Korean diabetes prevention study: a prospective, multi-center, randomized, openlabel controlled study. Diabetes Metab J 2019;43:49-58.

12. Carlsson LM, Peltonen M, Ahlin S, Anveden A, Bouchard C, Carlsson B, Jacobson P, Lonroth H, Maglio C, Naslund I, Pi- razzi C, Romeo S, Sjoholm K, Sjostrom E, Wedel H, Svensson PA, Sjostrom L. Bariatric surgery and prevention of type 2 diabetes in Swedish obese subjects. N Engl J Med 2012;367:695704.

13. le Roux CW, Astrup A, Fujioka K, Greenway F, Lau DCW, Van Gaal L, Ortiz RV, Wilding JPH, Skjoth TV, Manning LS, Pi-Sunyer X; SCALE Obesity Prediabetes NN8022-1839 Study Group. 3 Years of liraglutide versus placebo for type 2 diabetes risk reduction and weight management in individuals with prediabetes: a randomised, double-blind trial. Lancet 2017;389: 1399-409.

14. Abdullah A, Stoelwinder J, Shortreed S, Wolfe R, Stevenson C, Walls H, de Courten M, Peeters A. The duration of obesity and the risk of type 2 diabetes. Public Health Nutr 2011;14:119-26.

15. The NS, Richardson AS, Gordon-Larsen P. Timing and duration of obesity in relation to diabetes: findings from an ethnically diverse, nationally representative sample. Diabetes Care 2013;36:865-72. 